\title{
CD74 expression and its therapeutic potential in thyroid carcinoma
}

\author{
Shih-Ping Cheng ${ }^{1,3,4}$, Chien-Liang Liu, ${ }^{1,3}$, Ming-Jen Chen ${ }^{1,4,5}$, Ming-Nan Chien ${ }^{2,3}$, \\ Ching-Hsiang Leung ${ }^{2,3}$, Chi-Hsin Lin ${ }^{5}$, Yi-Chiung Hsu ${ }^{6}$ and Jie-Jen Lee ${ }^{1,3,4}$ \\ ${ }^{1}$ Department of Surgery, ${ }^{2}$ Division of Endocrinology and Metabolism, Department of Medicine, \\ MacKay Memorial Hospital and Mackay Medical College, Taipei, Taiwan \\ ${ }^{3}$ Mackay Junior College of Medicine, Nursing, and Management, No. 92, Sheng-Ching Road, Peitou, \\ Taipei 11260, Taiwan \\ ${ }^{4}$ Department of Pharmacology, Graduate Institute of Medical Sciences, Taipei Medical University, Taipei, Taiwan \\ ${ }^{5}$ Department of Medical Research, MacKay Memorial Hospital, Taipei, Taiwan \\ ${ }^{6}$ Institute of Statistical Science, Academia Sinica, Taipei, Taiwan
}

Correspondence

should be addressed

to J-J Lee

Email

surg.mmh@gmail.com

\begin{abstract}
CD74, the invariant chain of major histocompatibility complex class II, is also a receptor for macrophage migration inhibitory factor (MIF). CD74 and MIF have been associated with tumor progression and metastasis in hematologic and solid tumors. In this study, we found that 60 and $65 \%$ of papillary thyroid cancers were positive for CD74 and MIF immunohistochemical staining respectively. Anaplastic thyroid cancer was negative for MIF, but mostly positive for CD74 expression. Normal thyroid tissue and follicular adenomas were negative for CD74 expression. CD74 expression in papillary thyroid cancer was associated with larger tumor size $(P=0.043)$, extrathyroidal invasion $(P=0.021)$, advanced TNM stage $(P=0.006)$, and higher MACIS score $(P=0.026)$. No clinicopathological parameter was associated with MIF expression. Treatment with anti-CD74 antibody in thyroid cancer cells inhibited cell growth, colony formation, cell migration and invasion, and vascular endothelial growth factor secretion. In contrast, treatment with recombinant MIF induced an increase in cell invasion. Anti-CD74 treatment reduced AKT phosphorylation and stimulated AMPK activation. Our findings suggest that CD74 overexpression in thyroid cancer is associated with advanced tumor stage and may serve as a therapeutic target.
\end{abstract} Key Words

- CD74

- macrophage migration inhibitory factor

- thyroid cancer

antibody

\section{Introduction}

The majority of follicular cell-derived thyroid cancers is differentiated carcinomas and can be treated successfully with a combination of surgery and radioactive iodine therapy. For patients with advanced thyroid cancer, whose disease progresses despite standard therapy, treatment options are limited and survival is poor (Haugen \& Sherman 2013). Targeted therapies have begun receiving attention in recent years. Currently, the multikinase inhibitor sorafenib is the only targeted agent approved by the US Food and Drug Administration for the treatment of radioactive iodine-refractory differentiated thyroid cancer. Further fundamental research is needed to discover new therapeutic targets with better effectiveness and lower toxicity.

CD74, also known as the invariant chain of major histocompatibility complex (MHC) class II, functions as an MHC-II chaperone and participates in the trafficking of MHC-II molecules in antigen-presenting cells (Borghese \& Clanchy 2011). It has been shown that CD74 might be expressed independently of MHC-II, and CD74 can bind

Published by Bioscientifica Ltd. 
to non-MHC-II proteins (Ogrinc et al. 1993, Henne et al. 1995). Moreover, CD74 is a cell membrane receptor for macrophage migration inhibitory factor (MIF), a pleiotropic cytokine that has pro-inflammatory and pro-tumorigenic properties (Leng et al. 2003). This ligand-receptor interaction may be an important link between chronic inflammation and carcinogenesis (Bucala \& Donnelly 2007). The expression of MIF and/or CD74 has been explored in several forms of cancer (Ren et al. 2005, Xu et al. 2008, Nagata et al. 2009, Cheng et al. 2011a). In addition, MIF has been identified as a hypoxia-induced gene, and its expression serves to activate a proangiogenic transcriptional program (Winner et al. 2007).

In autoimmune thyroid disease, MIF production in response to thyroid antigens, but not to control antigens, has been described (Lamki et al. 1973). Recently, using a nationwide population-based study, we reported an increased risk for the development of thyroid cancer after a diagnosis of thyroiditis (Liu et al. 2014). Considering that MIF upregulation is associated with autoimmune thyroid disease and certain types of cancer, it is therefore interesting to investigate whether a differential expression of MIF and CD74 exists in thyroid cancer. Furthermore, the restricted expression of CD74 among normal tissues and its rapid internalization make CD74 an attractive therapeutic target for cancer therapy (Hansen et al. 1996). Milatuzumab, a humanized MAB that recognizes CD74, is currently under investigation. In a phase 1 trial, monotherapy with milatuzumab was able to stabilize advanced multiple myeloma (Kaufman et al. 2013). In this study, we evaluated the significance of MIF and CD74 expressions in thyroid cancer and the effects of anti-CD74 antibody on thyroid cancer cells.

\section{Materials and methods}

\section{Patients and tissue samples}

This study was approved by the Institutional Review Board (IRB) of MacKay Memorial Hospital (10MMHIS077). From January 2001 to November 2007, 334 patients underwent thyroidectomy with therapeutic intent for newly diagnosed differentiated thyroid cancer at our institution. Incidental microcarcinomas were excluded. Eligible patients were de-identified and randomly selected for entry into the study. Each patient had complete clinical and histopathological profile at diagnosis. Nonetheless, follow-up data were not available because of stringent de-identification of patient records. Finally, a total of 108 patients comprised our main study cohort. Lesions consisted of 103 papillary carcinomas and five anaplastic carcinomas. Of the 103 papillary carcinomas, ten showed a follicular structure and were diagnosed as follicular variant of papillary carcinoma. Lymph node metastasis was present in $58(56 \%)$ of 103 patients with papillary thyroid cancer. Among these patients, metastatic lymph nodes from 27 (47\%) patients were included for the immunohistochemical study. In addition, sections of five follicular adenomas and five samples from Graves' disease were submitted to immunohistochemical analysis.

For western blot analysis, total proteins were extracted from eight paired samples of papillary thyroid cancer, four paired samples of follicular adenoma, four samples from Hashimoto's thyroiditis, and four from Graves' disease. All were collected during surgery and immediately snap-frozen in liquid nitrogen.

\section{Cell culture and reagents}

Human papillary thyroid carcinoma cell lines BCPAP and K1 were purchased from the German Collection of Microorganisms and Cell Cultures (DSMZ, Braunschweig, Germany) and the European Collection of Cell Cultures (ECACC, Salisbury, UK) respectively. Both have been authenticated to be unique thyroid cancer cell lines (Schweppe et al. 2008). The expression of thyroid-specific genes is shown in Supplementary Figure S1, see section on supplementary data given at the end of this article. BCPAP harbored the homozygous mutation of BRAF, whereas $\mathrm{K} 1$ had the heterozygous mutation. BCPAP cells were cultured at $37^{\circ} \mathrm{C}$ in a humidified atmosphere of $5 \%$ $\mathrm{CO}_{2}$ in RPMI 1640 medium (Gibco; Life Technologies) supplemented with $10 \%$ fetal bovine serum (FBS). K1 cells were cultured in DMEM (Gibco) mixed with Ham's F12 (Sigma) and MCDB 105 (Sigma) medium in 2:1:1 proportions, supplemented with 10\% FBS and $2 \mathrm{mM}$ L-glutamine. Recombinant human MIF (\#289-MF) was purchased from R\&D Systems (Minneapolis, MN, USA). Anti-human CD74 antibody (specific for the extracellular domain of CD74, C-16; \#sc-5438) was obtained from Santa Cruz Biotechnology.

\section{Cell viability and colony formation assay}

Cell growth was determined using the thiazolyl blue tetrazolium (MTT) bromide colorimetric assay. Briefly, BCPAP and K1 cells (4000 cells/well) were seeded onto 96-well plates and were allowed to grow in complete culture media for $24 \mathrm{~h}$. Thereafter, the media was replaced with culture media containing 1\% FBS for a further

Published by Bioscientifica Ltd. 
24-72 h. The cells were treated with isotype control, recombinant human MIF $(200 \mathrm{ng} / \mathrm{ml})$, or anti-CD74 antibody $(5 \mu \mathrm{g} / \mathrm{ml})$. At the indicated time points, $100 \mu \mathrm{l}$ $(5 \mathrm{mg} / \mathrm{ml}$ ) of MTT reagent (Sigma) was added to the cell culture and cells were incubated at $37^{\circ} \mathrm{C}$ for $4 \mathrm{~h}$. Formazan crystals converted from tetrazolium salts by viable cells were solubilized with acidified isopropanol. The absorbance was measured at $570 \mathrm{~nm}$ by a Varioskan Flash microplate reader (Thermo Fisher Scientific, Waltham, MA, USA). The absorbance of control cells was defined as $100 \%$.

Colony formation assay was performed as previously described (Chang et al. 2014). In brief, BCPAP (1000 cells/ well) and K1 cells (500 cells/well) were seeded into six-well plates, allowed to adhere for $24 \mathrm{~h}$, and treated with isotype control, recombinant human MIF $(200 \mathrm{ng} / \mathrm{ml})$ or antiCD74 antibody $(5 \mu \mathrm{g} / \mathrm{ml})$ from day 2 . After 10-12 days, colonies were stained with $3 \%$ crystal violet and examined by microscopy. The colonies containing $>50$ cells were counted in five nonoverlapping fields.

\section{Wound healing assay}

Cell migration was determined using the wound healing assay, which was modified from our published method (Cheng et al. 2011b). BCPAP and K1 cells were trypsinized, counted, and seeded into six-well plates in culture media. After $24 \mathrm{~h}$, monolayers of cells were wounded using a sterile $300 \mu \mathrm{l}$ micropipette tip to scratch on the confluent cells. The culture media were replaced with the medium (1\% FBS) containing isotype control, recombinant human MIF $(200 \mathrm{ng} / \mathrm{ml})$, or anti-CD74 antibody $(5 \mu \mathrm{g} / \mathrm{ml})$ following scratch. The cells were photographed at 0,20 , 30,40 , and $48 \mathrm{~h}$. Wound closure measurement was performed in four different fields using ImageJ Software (National Institutes of Health, Bethesda, MD, USA).

\section{Invasion assay}

Cell invasion was assessed using the BioCoat Matrigel invasion chamber with $8 \mu \mathrm{m}$ pore diameter (\#354481; Corning Life Sciences, Tewksbury, MA, USA). A total of $1 \times 10^{5}$ cells were seeded onto the inserts in culture media containing 1\% FBS with isotype control, recombinant human MIF (200 ng/ml), or anti-CD74 antibody ( $5 \mu \mathrm{g} / \mathrm{ml})$. The inserts were placed into a six-well plate with $10 \%$ serum-containing culture medium as a chemoattractant. The plates were incubated for $24-48 \mathrm{~h}$ at $37^{\circ} \mathrm{C}$. The cells that invaded the Matrigel matrix to the lower surface of the membrane were fixed and stained with Diff-Quik
(Sysmex, Kobe, Japan), and counted under a light microscope in five nonoverlapping fields.

\section{Western blotting analysis}

Tissue or cellular proteins were extracted, quantified, and subjected to gel electrophoresis according to the standard procedures as we described previously (Cheng et al. 2012). A total of $30-50 \mu \mathrm{g}$ of total protein was separated by electrophoresis on 10-12\% SDS polyacrylamide gels. Fractionated proteins were transferred to a nitrocellulose membrane, and transfer was controlled by Ponceau staining. After transfer, the membrane was blocked with $5 \%$ skimmed milk or 5\% BSA for $30 \mathrm{~min}$ at room temperature. The proteins were probed with antibodies against MIF (\#ab55445; Abcam, Cambridge, MA, USA), CD74 (\#ab64103; Abcam), phospho-AKT $\left(\mathrm{Thr}^{308}\right.$ ) (\#4056; Cell Signaling, Danvers, MA, USA), phospho-AKT $\left(\mathrm{Ser}^{473}\right.$ ) (\#9271; Cell Signaling), total AKT (\#2920; Cell Signaling), phospho-AMPK $\alpha$ ( $\operatorname{Thr}^{172}$ ) (\#2531; Cell Signaling), total AMPK (\#2532; Cell Signaling), and $\beta$-actin (Sigma) at $4{ }^{\circ} \mathrm{C}$ overnight. The results were visualized by chemiluminescence with the Amersham ECL Detection System (GE Healthcare, Piscataway, NJ, USA). The blot signals were quantified by densitometry (ImageJ Software) and normalized to $\beta$-actin.

\section{Cytokine detection}

Vascular endothelial growth factor (VEGF) concentrations were determined using an ELISA (\#DVE00; R\&D Systems) according to the manufacturer's instructions. The cell culture supernatants were collected after each experiment and centrifuged to remove cells and debris. The optical density (OD) was measured at $450 \mathrm{~nm}$ and concentrations extrapolated from a standard curve. The sensitivity of the assays was $9 \mathrm{pg} / \mathrm{ml}$.

\section{Immunohistochemistry}

The expression of MIF and CD74 in tissue sections was studied by immunohistochemical staining as described previously (Cheng et al. 2013). Briefly, $5 \mu \mathrm{m}$ sections of paraffin-embedded tissue blocks were deparaffinized in xylene and rehydrated in a graded series of ethanol. For antigen retrieval, the slides were immersed in a Tris-EDTA Buffer (10 mM Tris base, $1 \mathrm{mM}$ EDTA solution, 0.05\% Tween 20, and $\mathrm{pH} 9$ ) and boiled for $20 \mathrm{~min}$ in a pressure cooker while maintaining the pressure. Endogenous peroxidase activity was quenched with $3 \%$ hydrogen

Published by Bioscientifica Ltd. 
peroxidase in methanol for $10 \mathrm{~min}$. The slides were then incubated with primary antibodies against MIF (\#ab55445; Abcam) and CD74 (\#ab64103; Abcam) in humid chambers at $4{ }^{\circ} \mathrm{C}$ overnight. The slides were washed and further incubated with goat-anti-mouse MACH2 HRP polymer (Biocare Medical, Concord, CA, USA) for $30 \mathrm{~min}$ at room temperature. The chromogenic reaction was done with 0.02\% 3,3'-diaminobenzidine (Sigma) for $30 \mathrm{~min}$. All slides were counterstained with hematoxylin, dehydrated, cleared, and cover slipped. Negative control slides in the absence of primary or secondary antibody were included for each staining.

\section{Evaluation of immunostaining}

Cytoplasmic immunoreactivity was evaluated semiquantitatively as previously reported (Cheng et al. 2013). Staining intensity was scored as 0 (no staining), 1 (weak), 2 (moderate), and 3 (strong). Staining proportion was scored as 0 (<1\%), 1 (1-25\%), 2 (26-50\%), and 3 (>50\%), according to the percentage of positively stained cells. Multiplied scores of intensity and proportion were used as the final staining score. Positive expression was defined by final staining scores 6 and 9, whereas the remaining cases (final scores 0-4) were classified as negative expression.

\section{Analysis of publicly available gene expression datasets}

We accessed the National Center for Biotechnology Information Gene Expression Omnibus (http://www.ncbi.nlm. nih.gov/geo/) and identified publicly available thyroid cancer datasets. GSE3678 comprises gene expression data of seven paired samples of papillary thyroid cancer. GSE3467 (He et al. 2005) comprises gene expression data of nine paired samples of papillary thyroid cancer. GSE33630 (Hebrant et al. 2012) comprises gene expression data of 45 normal thyroid and 49 papillary thyroid cancer samples obtained from Ukraine via the Chernobyl Tissue Bank, as well as 11 anaplastic thyroid cancer samples from different hospitals in France and Belgium. Affymetrix Human Genome U133 Plus 2.0 Arrays were used in these datasets.

\section{Statistical analyses}

Categorical patient characteristics are expressed as proportions, while continuous variables are expressed as medians with 25th and 75th percentiles (defining the interquartile range). $\chi^{2}$, Fisher's exact test, or CochranArmitage trend test was used to compare categorical variables. Continuous variables were compared using the
Mann-Whitney $U$ test or Student's $t$-test. The Kendall's $\tau$-b test was used to determine the relationship between expressions of markers. Throughout the analysis, $P$ values $<0.05$ (two-sided hypotheses) were considered to be statistically significant. Statistical analyses were performed using STATA for Windows, release 11 (Stata Corp., College Station, TX, USA).

\section{Results}

\section{Expression analysis using microarray database}

Relative expression of MIF and CD74 was examined in different sets of thyroid carcinoma using microarray database GSE3678, GSE3467, and GSE33630 downloaded from the Gene Expression Omnibus database. There was no significant difference in the expression level of MIF between normal thyroid and papillary carcinoma, whereas CD74 expression was significantly increased in papillary carcinoma compared with normal thyroid (Fig. 1). Anaplastic cancer samples showed significantly lower
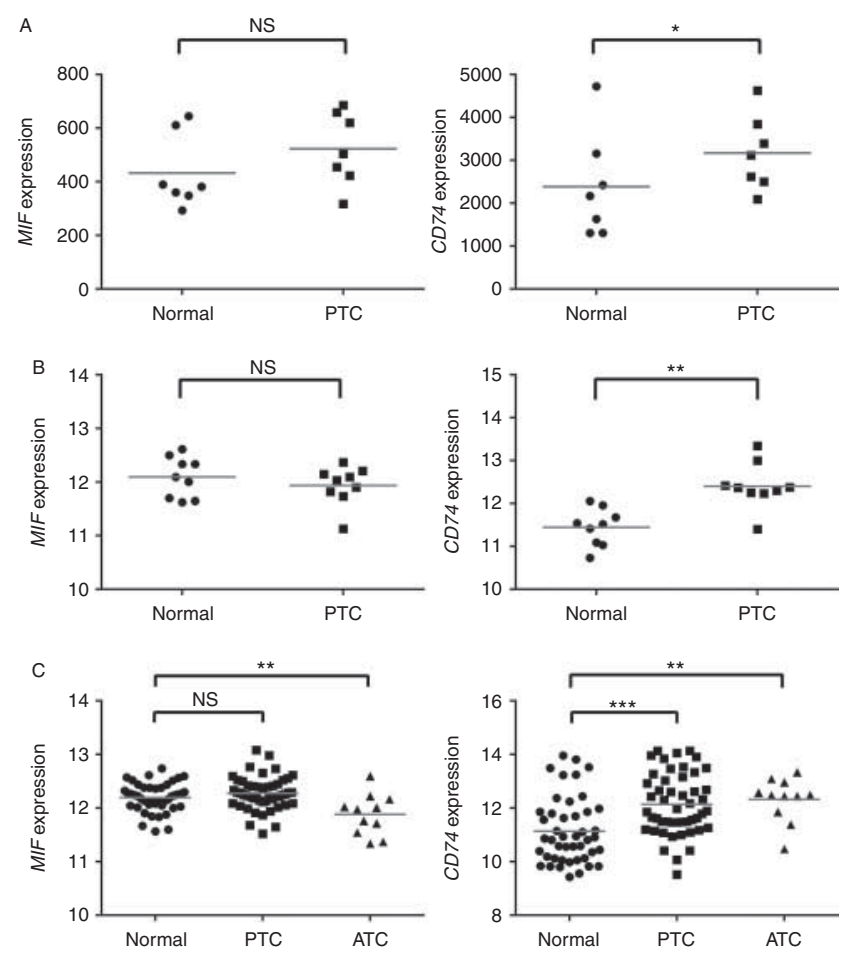

Figure 1

Gene expression levels of macrophage migration inhibitory factor (MIF) and CD74 in normal thyroid, papillary thyroid cancer (PTC), and anaplastic thyroid cancer (ATC). Three different datasets were examined: (A) GSE3678 dataset, (B) GSE3467 dataset (He et al. 2005), and (C) GSE33630 dataset (Hebrant et al. 2012). $P$ values were determined by the Mann-Whitney $U$ test. $* P<0.05, * * P<0.01$, and $* * * P<0.001$; NS, non-significant.

Published by Bioscientifica Ltd 
expression of MIF and higher expression of CD74 as compared with normal thyroid specimens (Fig. 1C).

\section{Tissue expression in thyroid cancer}

Immunohistochemical staining for MIF and CD74 was performed in 103 papillary cancers, 27 corresponding metastatic lymph nodes, and five anaplastic cancers. Based on our predetermined criteria, 67 (65\%) and 62 (60\%) papillary cancers were positive for MIF and CD74 staining respectively (Fig. 2A). In all, 44 (43\%) exhibited both MIF and CD74 expression. There was no correlation between the expression of MIF and CD74 $(P=0.124)$. Among patients with papillary cancer, lymph nodes positive for metastasis were randomly selected from 27 patients and subjected to immunohistochemical analysis. We observed that MIF immunoreactivity appeared in 25 (93\%) of 27 patients, whereas positive CD74 expression was evident in 21 (78\%). There was no significant correlation in MIF or CD74 expression between the primary tumor and metastatic lymph nodes ( $P=0.828$ and $P=0.946$ respectively).
In the five anaplastic cancers, three showed no MIF staining within anaplastic components, and two had faint staining, which was also classified as negative expression. Positive CD74 immunoreactivity was present in 4 (80\%) of five cases. Our findings are consistent with those of microarray gene expression data. Additional five follicular adenomas and five samples from Graves' disease were analyzed. MIF immunoreactivity was positive in four follicular adenomas and three samples from Graves' disease respectively. No CD74 positive staining was noted in these tissue samples of benign thyroid lesions (Supplementary Figure S2, see section on supplementary data given at the end of this article). Our findings suggest that CD74 overexpression in thyroid cancer is relatively specific to malignant transformation.

Western blotting analysis was used to evaluate the expression of MIF and CD74 in eight paired (normal and tumor) samples of papillary thyroid cancer (Fig. 2B). There was a trend toward increased MIF and CD74 expression in the tumor part. It is noteworthy that CD74 expression was barely detectable in the normal thyroid tissue.
A
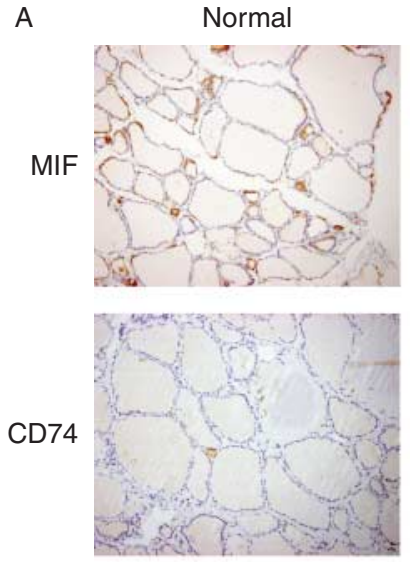

PTC
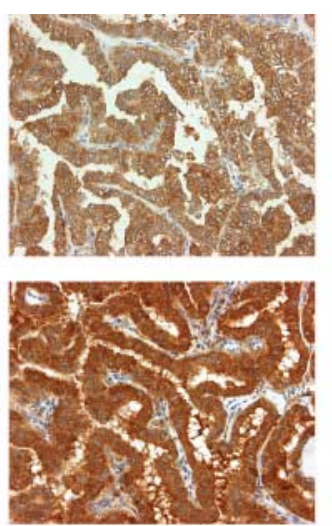

Lymph node
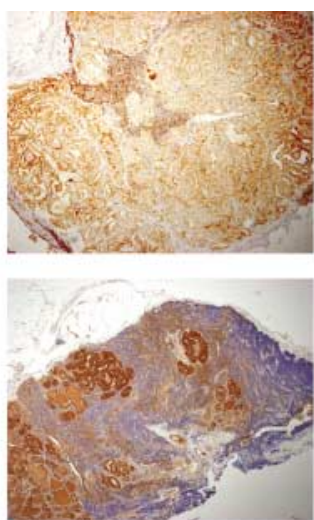

ATC
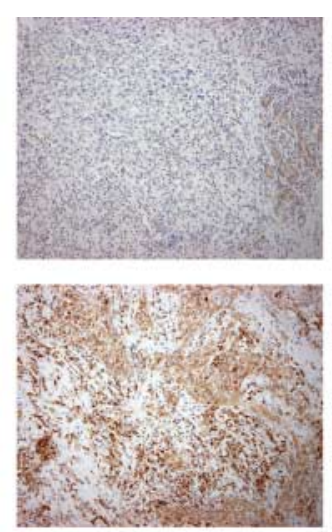

B
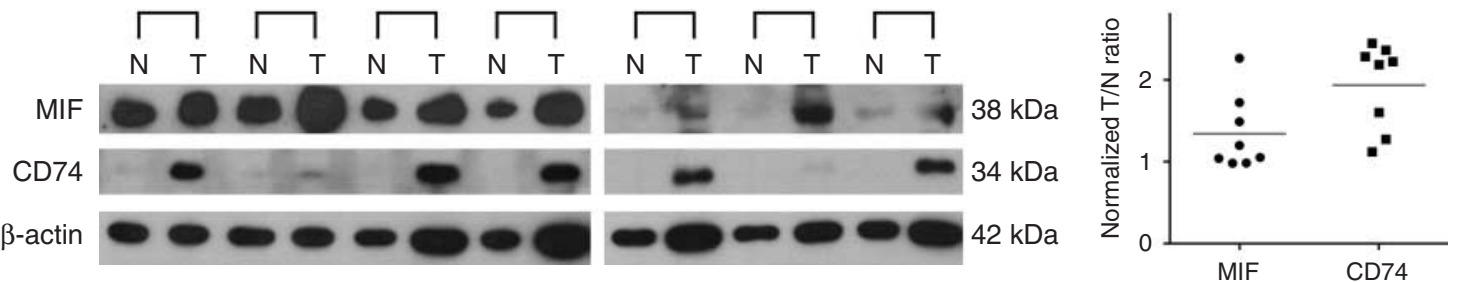

\section{Figure 2}

Tissue expression of macrophage migration inhibitory factor (MIF) and CD74 in thyroid cancer. (A) Representative microphotographs of immunohistochemical staining in normal thyroid, papillary thyroid cancer (PTC), metastatic lymph node, and anaplastic thyroid cancer (ATC). Original magnification, $100 \times$ for normal thyroid, $200 \times$ for PTC, $40 \times$ for lymph node, and $100 \times$ for ATC. (B) Protein expression determined by western blotting analysis in paired PTC samples ( $\mathrm{T}$, tumor; N, adjacent normal thyroid tissue). Bands were quantified by densitometry and normalized to the $\beta$-actin levels. T: $N$ ratios were plotted on a vertical scatter plot. Horizontal bars indicate the mean for each group. A full colour version of this figure is available at http://dx.doi.org/10.1530/ERC-14-0269. http://erc.endocrinology-journals.org DOI: $10.1530 /$ ERC-14-0269
(C) 2015 Society for Endocrinology Printed in Great Britain
Published by Bioscientifica Ltd 
Table 1 Correlation of macrophage migration inhibitory factor (MIF) expression with clinicopathological parameters in patients with papillary thyroid carcinoma $(n=103)$

\begin{tabular}{|c|c|c|c|}
\hline & MIF $(+)(n=67)$ & $\operatorname{MIF}(-)(n=36)$ & $P$ value \\
\hline Female & $52(78 \%)$ & $29(81 \%)$ & 0.728 \\
\hline Age (years) ${ }^{a}$ & $41(33-49)$ & $40(30-51)$ & 0.561 \\
\hline Hashimoto's thyroiditis & $3(4 \%)$ & $3(8 \%)$ & 0.419 \\
\hline Tumor size $(\mathrm{cm})^{\mathrm{a}}$ & $2.5(2.0-3.2)$ & $2.1(1.8-2.6)$ & 0.111 \\
\hline Extrathyroidal invasion ${ }^{\mathrm{b}}$ & & & 0.100 \\
\hline No & $41(61 \%)$ & $27(75 \%)$ & \\
\hline Microscopic & $19(28 \%)$ & $9(25 \%)$ & \\
\hline Macroscopic & $7(10 \%)$ & $0(0 \%)$ & \\
\hline Multifocality & $22(33 \%)$ & $15(42 \%)$ & 0.373 \\
\hline Lymph node metastasis $^{\mathrm{b}}$ & & & 0.610 \\
\hline NO & $29(43 \%)$ & $16(44 \%)$ & \\
\hline N1a & $25(37 \%)$ & $16(44 \%)$ & \\
\hline N1b & $13(19 \%)$ & $4(11 \%)$ & \\
\hline Distant metastasis & $2(3 \%)$ & $0(0 \%)$ & 0.541 \\
\hline TNM stage ${ }^{b}$ & & & 0.189 \\
\hline Stage 1 & $46(69 \%)$ & $29(81 \%)$ & \\
\hline Stage 2 & $5(7 \%)$ & $2(6 \%)$ & \\
\hline Stage 3 & $9(13 \%)$ & $3(8 \%)$ & \\
\hline Stage 4 & $7(10 \%)$ & $2(6 \%)$ & \\
\hline MACIS score ${ }^{a}$ & $4.8(4.0-5.9)$ & $4.5(3.9-5.5)$ & 0.252 \\
\hline MACIS $\geq 6$ & $15(22 \%)$ & $4(11 \%)$ & 0.191 \\
\hline
\end{tabular}

Data are expressed as number (percentage) or median (interquartile range). MACIS, Mayo Clinic's metastasis, patient age, completeness of resection, local invasion, and tumor size.

a Mann-Whitney $U$ test.

${ }^{\mathrm{b}}$ Cochran-Armitage trend test.

An inconsistent pattern of MIF expression was observed in samples of follicular adenoma, Hashimoto's thyroiditis, and Graves' disease (Supplementary Figure S2). These benign thyroid lesions did not show CD74 expression.

\section{Clinicopathological correlations}

To investigate the potential role of MIF and CD74 in thyroid cancer, the 103 samples of papillary cancer were divided into two groups with positive and negative MIF/CD74 expression and compared for a series of clinicopathological parameters. As given in Table 1, we have not observed any parameter that was associated with the MIF expression. However, papillary cancer positive for CD74 expression was associated with larger tumor size, higher rate of extrathyroidal invasion, and more advanced TNM stage (Table 2). MACIS scoring system developed at the Mayo Clinic uses metastasis, age, completeness of resection, local invasion, and tumor size to stratify patients by different survival (Hay et al. 1993). In accordance, CD74positive thyroid cancer had significantly higher MACIS scores $(P=0.026)$. The expression of MIF or CD74 was not associated with follicular variant or the presence of concurrent lymphocytic thyroiditis. Given that CD74 is overexpressed in thyroid cancer and associated with advanced tumor stage, we hypothesize that CD74 might be a potential therapeutic target in thyroid cancer.

\section{Reduced cell growth with anti-CD74 antibody treatment}

Two papillary thyroid cancer cell lines, BCPAP and K1, were evaluated for the expression of CD74. Both thyroid cancer cells were positive for CD74 expression (Supplementary Figure S3). Treatment with MIF did not alter the CD74 expression, whereas anti-CD74 neutralizing antibody (which binds the CD74 extracellular domain) remarkably decreased the CD74 expression in both cell lines.

We then tested the effects of MIF and anti-CD74 antibody on cell growth. Both cells were treated with vehicle (PBS) control, isotype control, recombinant human MIF, or anti-CD74 antibody. The results of vehicle control and isotype control were similar, and thus only the results of isotype control were shown. As shown in Fig. 3A, treatment with anti-CD74 antibody significantly suppressed cell growth after $48 \mathrm{~h}$. There was no significant

Table 2 Correlation of CD74 expression with clinicopathological parameters in patients with papillary thyroid carcinoma $(n=103)$

\begin{tabular}{|c|c|c|c|}
\hline & $\begin{array}{c}\text { CD74 (+) } \\
(n=62)\end{array}$ & $\begin{array}{c}\text { CD74 }(-) \\
(n=41)\end{array}$ & $P$ value \\
\hline Female & $50(81 \%)$ & $31(76 \%)$ & 0.542 \\
\hline Age (years) ${ }^{a}$ & $42(33-51)$ & $37(31-47)$ & 0.103 \\
\hline Hashimoto's thyroiditis & $4(6 \%)$ & $2(5 \%)$ & 1.000 \\
\hline Tumor size $(\mathrm{cm})^{a}$ & $2.5(2.0-3.2)$ & $2.1(1.5-2.5)$ & 0.043 \\
\hline Extrathyroidal invasion ${ }^{b}$ & & & 0.021 \\
\hline No & $36(58 \%)$ & $32(78 \%)$ & \\
\hline Microscopic & $19(31 \%)$ & $9(22 \%)$ & \\
\hline Macroscopic & $7(11 \%)$ & $0(0 \%)$ & \\
\hline Multifocality & $20(32 \%)$ & $17(41 \%)$ & 0.341 \\
\hline Lymph node metastasis $^{\mathrm{b}}$ & & & 0.930 \\
\hline No & $28(45 \%)$ & $17(41 \%)$ & \\
\hline N1a & $22(35 \%)$ & $19(46 \%)$ & \\
\hline N1b & $12(19 \%)$ & $5(12 \%)$ & \\
\hline Distant metastasis & $2(3 \%)$ & $0(0 \%)$ & 0.516 \\
\hline TNM stage $^{b}$ & & & 0.006 \\
\hline Stage 1 & $39(63 \%)$ & $36(88 \%)$ & \\
\hline Stage 2 & $6(10 \%)$ & $1(2 \%)$ & \\
\hline Stage 3 & $9(15 \%)$ & $3(7 \%)$ & \\
\hline Stage 4 & $8(13 \%)$ & $1(2 \%)$ & \\
\hline MACIS score ${ }^{a}$ & $5.1(4.0-6.0)$ & $4.4(3.9-5.2)$ & 0.026 \\
\hline MACIS $\geq 6$ & $16(26 \%)$ & $3(7 \%)$ & 0.020 \\
\hline
\end{tabular}

Data are expressed as number (percentage) or median (interquartile range). MACIS, Mayo Clinic's metastasis, patient age, completeness of resection, local invasion, and tumor size.

${ }^{a}$ Mann-Whitney test.

${ }^{\mathrm{b}}$ Cochran-Armitage trend test. 
A

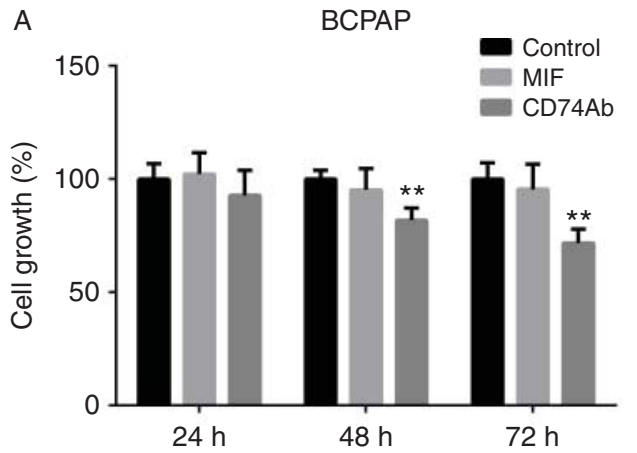

B

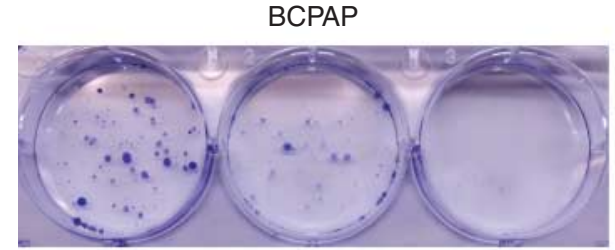

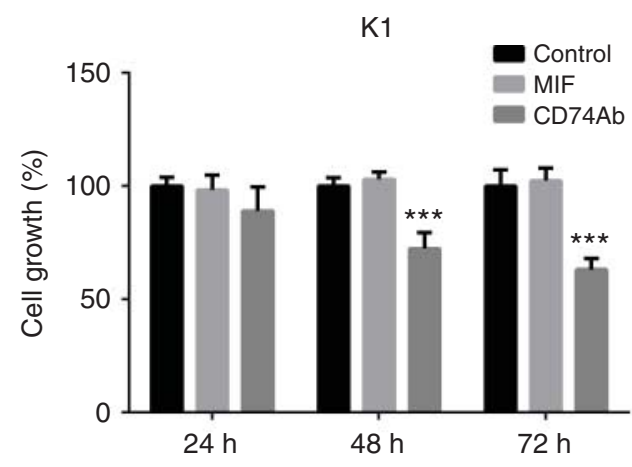

$\mathrm{K} 1$
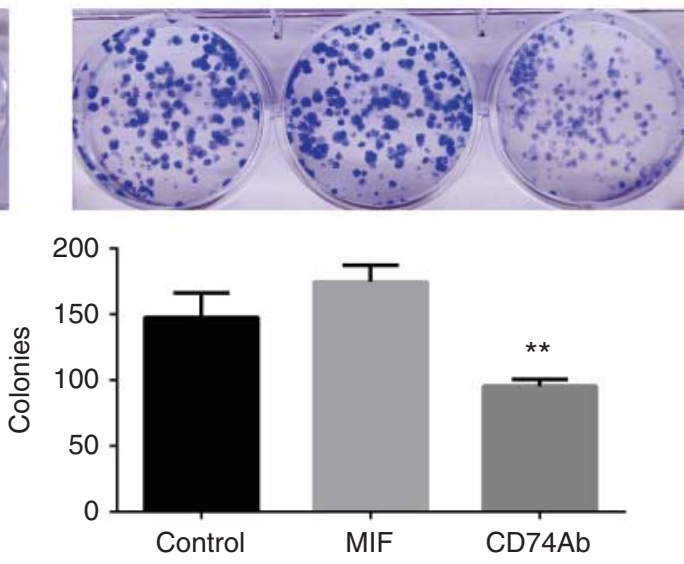

Figure 3

Effects of CD74 modulation on cell growth and colony formation in human thyroid cancer cells. (A) BCPAP and K1 cells were treated with isotype control, recombinant human macrophage migration inhibitory factor (MIF, $200 \mathrm{ng} / \mathrm{ml}$ ), or anti-CD74 antibody (CD74Ab, $5 \mu \mathrm{g} / \mathrm{ml}$ ) for 24-72 h. Cell viability, determined with thiazolyl blue tetrazolium (MTT) assay,

effect on cell growth with MIF treatment. In concordance with the results of MTT assay, treatment with anti-CD74 antibody inhibited anchorage-dependent colony formation by $86 \%$ in BCPAP cells and 35\% in K1 cells (Fig. 3B). In addition, the size of colonies in anti-CD74 antibody-treated cells was smaller as compared with isotype control-treated cells. Paradoxically, clonogenic assays showed that MIF treatment significantly reduced the colony numbers by $32 \%$ in BCPAP cells but not in K1 cells.

\section{Decreased cell migration and invasion with anti-CD74 antibody treatment}

In the same experimental conditions using MTT assay, cell migration and invasion were evaluated in thyroid cancer cells. With treatment with anti-CD74 antibody, cell migration was reduced by $34 \%$ in BCPAP cells and $29 \%$ in $\mathrm{K} 1$ cells (Fig. 4A). MIF treatment had no effect on was calculated by comparing results with control cells ( $100 \%$ viable). (B) Quantification of colonies formed following treatment with isotype control, MIF, or CD74Ab in BCPAP and K1 cells. $P$ values were determined by the Student's $t$-test. ${ }^{*} P<0.05, * * P<0.01$, and $* * * P<0.001$. A full colour version of this figure is available at http://dx.doi.org/10.1530/ERC-14-0269.

cell migration. Similarly, treatment with anti-CD74 antibody significantly reduced the invasiveness through matrigel (BCPAP, 48\% and K1, 35\%) compared with controls (Fig. 4B). Interestingly, treatment with recombinant human MIF led to a remarkable increase in invasion in both BCPAP (67\% increase) and K1 (69\% increase) cells.

\section{Decreased VEGF secretion with anti-CD74 antibody treatment}

Previous study showed that MIF induced VEGF secretion in a dose-dependent manner in cervical cancer cells, which could be inhibited by anti-CD74 antibody (Cheng et al. 2011a). To study the effects on VEGF secretion in thyroid cancer, BCPAP and K1 cells were treated with the same experimental protocol previously used. As shown in Fig. 5A, MIF did not stimulate VEGF secretion in thyroid cancer cells. However, treatment with

Published by Bioscientifica Ltd. 
A

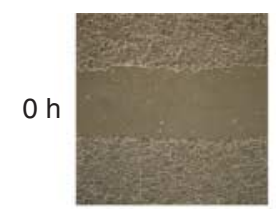

BCPAP
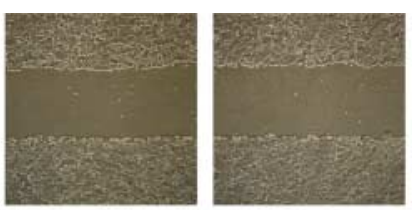

$20 \mathrm{~h}$
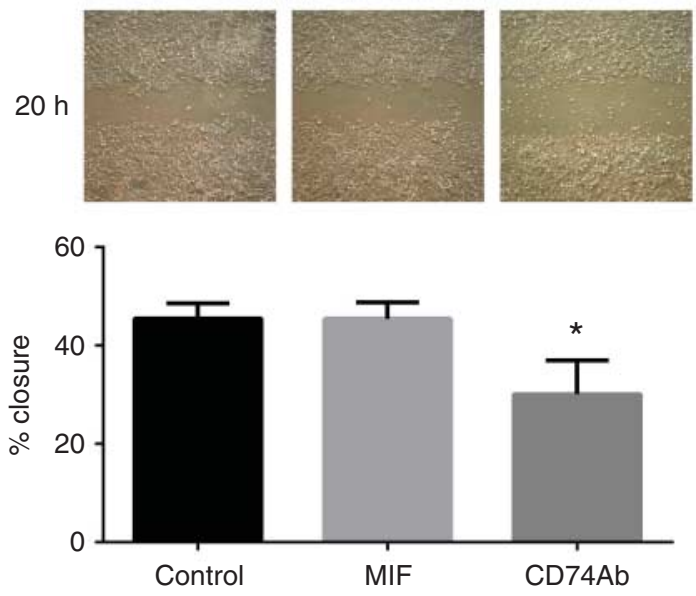

B
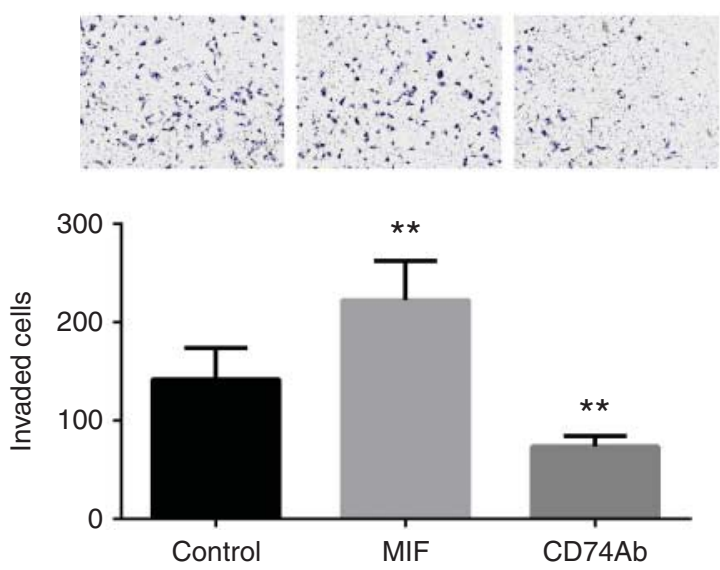

\section{Figure 4}

Effects of CD74 modulation on cellular migration and invasion in human thyroid cancer cells. (A) Quantification of wound closure in BCPAP and $\mathrm{K} 1$ cells treated with isotype control, recombinant human macrophage migration inhibitory factor (MIF, $200 \mathrm{ng} / \mathrm{ml}$ ), or anti-CD74 antibody

anti-CD74 antibody modestly decreased VEGF secretion by $29 \%$ in BCPAP cells and 12\% in K1 cells.

\section{Survival pathways involved in CD74 modulation}

To investigate the mechanisms involved in CD74 modulation, the expression of the phosphorylation of AKT and AMPK was determined following treatment with antiCD74 antibody. Stimulation of surface CD74 induces a signaling cascade resulting in AKT activation and cell
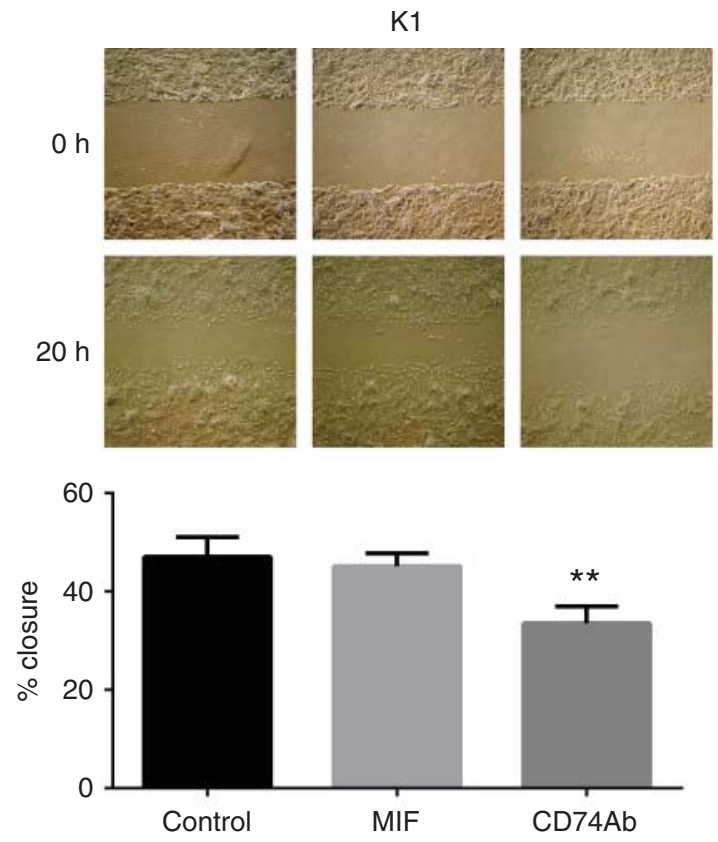

$\mathrm{K} 1$
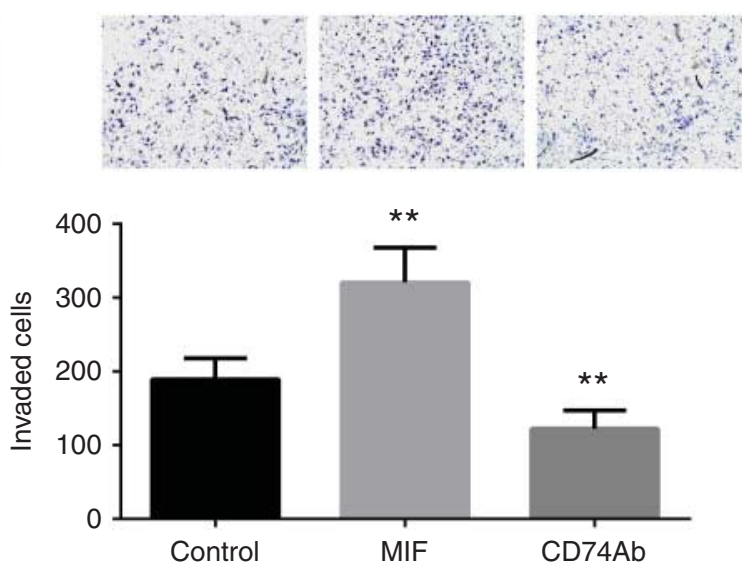

(CD74Ab, $5 \mu \mathrm{g} / \mathrm{ml}$ ). (B) Quantification of invaded cells following treatment with isotype control, MIF, or CD74Ab for $48 \mathrm{~h}$. $P$ values were determined by the Student's $t$-test. ${ }^{*} P<0.05$ and ${ }^{*} * P<0.01$. A full colour version of this figure is available at http://dx.doi.org/10.1530/ERC-14-0269.

proliferation (Starlets et al. 2006). Furthermore, impaired AMPK activation was observed in the hearts of CD74knockout mice during ischemia (Qi et al. 2014). Decreased AKT Thr ${ }^{308}$ phosphorylation was observed following antiCD74 antibody treatment, while AKT Ser ${ }^{473}$ phosphorylation was slightly reduced (Fig. 5B). In addition, AMPK phosphorylation increased upon stimulation with antiCD74 antibody in both cell lines. There was no change in the expression of total AKT or total AMPK. These results indicate that PI3K/AKT and AMPK pathways may play a

Published by Bioscientifica Ltd 
A

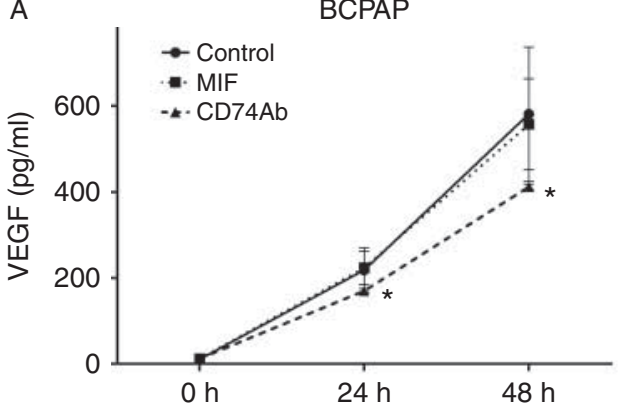

B

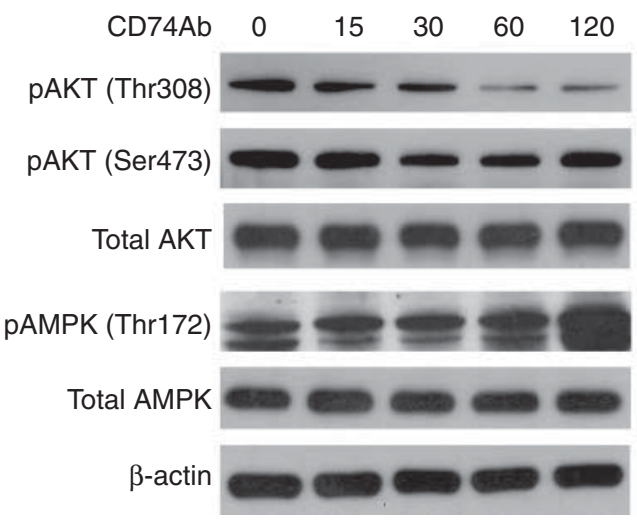

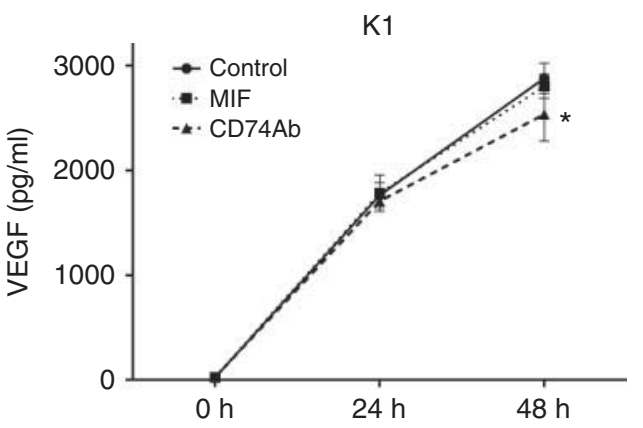

K1

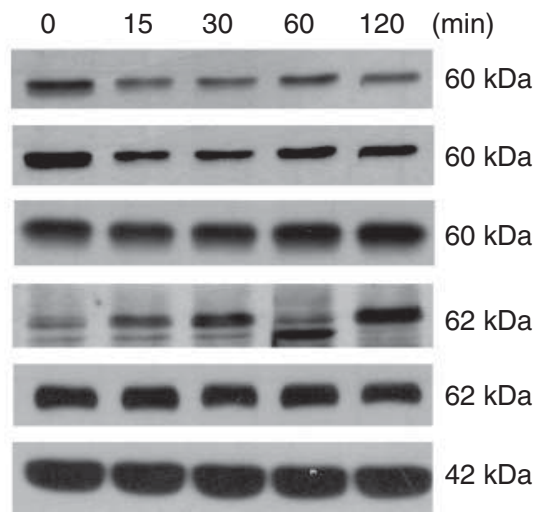

\section{Figure 5}

Effects of CD74 modulation on vascular endothelial growth factor (VEGF) secretion and various kinases in human thyroid cancer cells. (A) BCPAP and $\mathrm{K} 1$ cells were treated with isotype control, recombinant human macrophage migration inhibitory factor (MIF, $200 \mathrm{ng} / \mathrm{ml}$ ), or anti-CD74 antibody (CD74Ab, $5 \mu \mathrm{g} / \mathrm{ml}$ ) for $24-48 \mathrm{~h}$. The secretion of VEGF in the culture

role in the inhibitory effects seen following treatment with anti-CD74 antibody.

\section{Discussion}

In this study, we for the first time demonstrated that CD74 was overexpressed in tumorous parts of thyroid malignancy and was associated with advanced tumor stage. Our initial hypothesis was that MIF may represent a link between inflammation and thyroid cancer. MIF binds to CD74, and correlations between the expression of CD74 and MIF have been reported (Cheng et al. 2011a, Zheng et al. 2012). However, based on our results, CD74 expression did not correlate with MIF expression in thyroid cancer. Furthermore, anaplastic thyroid cancer showed a decreased MIF expression. CD74 expression is generally observed in tumor with advanced stage and worse survival (Nagata et al. 2009, Zheng et al. 2012). On the other hand, intracellular MIF expression may have medium was analyzed by ELISA. $P$ values were determined by the Student's $t$-test. ${ }^{*} P<0.05$. (B) Cells were treated with CD74Ab for various times. Protein extraction and western blotting were performed as described in Materials and methods section.

different implications from exogenous MIF stimulation. For instance, breast cancer with abundant cytosolic MIF expression was associated with better disease-specific overall and recurrence-free survival (Verjans et al. 2009). Considering that there was no significant difference in clinicopathological parameters between MIF-positive and MIF-negative tumors, MIF probably plays a minor role in thyroid cancer development and progression. CD74 instead might be more appropriate for therapeutic intervention in thyroid cancer.

We observed that treatment with anti-CD74 antibody inhibited cell growth, migration, and invasion in thyroid cancer cells. In DU-145 prostate cancer cells, anti-CD74 treatment reduced cell viability to the extent similar to that observed following knockdown of CD74 by RNA interference (Meyer-Siegler et al. 2006). Furthermore, antiCD74 treatment successfully suppressed cell invasion in prostate cancer cells expressing cell surface CD74. In MKN45 gastric cancer cells, lipopolysaccharide-induced cell

Published by Bioscientifica Ltd. 
proliferation was similarly reduced with either knockdown of CD74 or anti-CD74 treatment (Zheng et al. 2012). Antibody therapeutics in cancer is used to specifically target a molecule with antigenic differences between normal and malignant tissues (Sliwkowski \& Mellman 2013). Moreover, CD74 is a suitable carrier for antibodydrug conjugates for its high expression on neoplastic cells and rapid internalization. Various chemotherapeutic or radioactive agents have been used to prepare a conjugate in hematologic and solid tumors (Govindan et al. 2013). Despite our intriguing findings suggesting relatively specific expression of CD74 in malignant thyroid cancer tissues, further in vivo studies are warranted to evaluate the efficacy and safety of targeting CD74 in thyroid cancer.

Cancer-induced immune stimulation and suppression may lead to local and systemic cytokine alterations. Among cytokine alterations associated with malignancy, significantly increased serum MIF concentrations have been reported in several types of cancer (Lippitz 2013). In esophageal and breast cancer, tissue MIF expression correlated with microvessel density (Ren et al. 2005, Xu et al. 2008). In cervical cancer, either MIF or CD74 expression was positively associated with higher microvessel density (Cheng et al. 2011a). MIF has been shown to interact with and stabilize hypoxia-inducible factor 1 alpha, a master regulator of hypoxic/ischemic vascular responses (Winner et al. 2007). In this study, MIF treatment did not induce VEGF secretion in thyroid cancer cells. In contrast, anti-CD74 antibody modestly reduced the secretion of VEGF. Our findings are consistent with those of Kindt et al. (2014) that CD74 knockdown reduced VEGF production from SCCVII cells. A large body of evidence indicates that VEGF plays a critical role in angiogenesis and metastasis (Phay \& Ringel 2013). Clinical applications of VEGF in thyroid cancer have included diagnosis, prediction of prognosis, and treatment (Lin \& Chao 2005). Collectively, these findings provide further evidence that CD74 may serve as a potential target for the intervention of thyroid cancer.

AKT signaling plays an important role in the progression of thyroid cancer (Shinohara et al. 2007). It was shown that MIF prevents apoptosis and promotes tumor cell survival by directly activating the AKT pathway (Lue et al. 2007). The function of AKT is regulated by phosphorylation on two sites. Maximal AKT activity requires $\mathrm{Thr}^{308}$ phosphorylation mediated by PDK1 and Ser ${ }^{473}$ phosphorylation by mTOR complex 2 (mTORC2; Manning \& Cantley 2007). It has been shown that stimulation of surface CD74 induced a signaling cascade resulting in AKT activation and cell proliferation (Starlets et al. 2006). CD74 (but not MIF) stimulation induced upregulation of monocyte chemoattractant protein 1, which was prevented by an AKT inhibitor (Martin-Ventura et al. 2009). Our data are in concordance with these results and suggested an association between inhibition of PI3K/AKT pathway and suppressive effects following treatment with anti-CD74 antibody.

AMPK is a master energy sensor and functions to monitor and maintain cellular and organismal metabolism. AKT negatively regulates AMPK by decreasing the AMP:ATP ratio (Hahn-Windgassen et al. 2005). In this respect, we found that anti-CD74 treatment inhibited AKT phosphorylation and meanwhile activated the AMPK pathway. MIF stimulation activates the cardioprotective AMPK pathway during ischemia (Miller et al. 2008). Nonetheless, AMPK activation had a greater degree of impairment in $C D 74^{-/-}$than $M I F^{-/-}$hearts during ischemia (Qi et al. 2014). The sequence or interaction of AKT inhibition and AMPK activation could not be determined in this study. In the opposite direction, AMPK may suppress AKT activity through activation of PTEN or protein phosphatase 2A (Huang et al. 2008, Kim et al. 2009). AMPK agonists are currently under investigation for cancer treatment. Metformin use in diabetic patients with thyroid cancer is associated with higher remission rate (Klubo-Gwiezdzinska et al. 2013). The role of AMPK activation in tumor suppressive effects associated with CD74 modulation remains to be clarified.

One limitation of our study is that follow-up data are not available for analysis. Therefore, we could not affirm whether patients with a CD74-positive tumor have a worse overall or disease-specific survival. Furthermore, the number of benign thyroid lesions studied is small. The specificity of CD74 overexpression in malignant thyroid tissue needs to be verified in a larger series of tumors. We observed CD74 overexpression in $60 \%$ of the primary papillary cancer and $78 \%$ of the corresponding metastatic lymph nodes. There was no association of CD74 expression between the primary tumor and metastatic nodes. It is unclear whether CD74 overexpression develops de novo during metastasis or CD74-positive cells carrying greater migratory/invading capacity are selected in the metastatic process.

In summary, we report the characterization of CD74 expression in thyroid cancer and demonstrate that treatment with anti-CD74 antibody effectively modulates malignant cell phenotype. Although the findings appear to rebut the initial hypothesis that MIF/CD74 mediates the link between inflammation and thyroid cancer, our

Published by Bioscientifica Ltd. 
results indicate that CD74 may serve as a therapeutic target molecule in advanced thyroid cancer.

\section{Supplementary data}

This is linked to the online version of the paper at http://dx.doi.org/10.1530/ ERC-14-0269.

\section{Declaration of interest}

The authors declare that there is no conflict of interest that could be perceived as prejudicing the impartiality of the research reported.

\section{Funding}

This study was supported by grants from the National Science Council of Taiwan (NSC-100-2314-B-195-001-MY3 and MOST-103-2314-B-195-015MY3) and MacKay Memorial Hospital (MMH-10303 and MMH-10423).

\section{Acknowledgements}

Part of the data of this study was presented in oral form at the 49th International Congress of European Society for Surgical Research, Budapest, Hungary, May 2014.

\section{References}

Borghese F \& Clanchy FI 2011 CD74: an emerging opportunity as a therapeutic target in cancer and autoimmune disease. Expert Opinion on Therapeutic Targets 15 237-251. (doi:10.1517/14728222.2011. 550879)

Bucala R \& Donnelly SC 2007 Macrophage migration inhibitory factor: a probable link between inflammation and cancer. Immunity 26 281-285. (doi:10.1016/j.immuni.2007.03.005)

Chang YC, Hsu YC, Liu CL, Huang SY, Hu MC \& Cheng SP 2014 Local anesthetics induce apoptosis in human thyroid cancer cells through the mitogen-activated protein kinase pathway. PLoS ONE 9 e89563. (doi:10.1371/journal.pone.0089563)

Cheng RJ, Deng WG, Niu CB, Li YY \& Fu Y 2011 $a$ Expression of macrophage migration inhibitory factor and CD74 in cervical squamous cell carcinoma. International Journal of Gynecological Cancer 21 1004-1012. (doi:10.1097/IGC.0b013e31821c45b7)

Cheng SP, Yin PH, Hsu YC, Chang YC, Huang SY, Lee JJ \& Chi CW $2011 b$ Leptin enhances migration of human papillary thyroid cancer cells through the PI3K/AKT and MEK/ERK signaling pathways. Oncology Reports 26 1265-1271. (doi:10.3892/or.2011.1388)

Cheng SP, Liu CL, Hsu YC, Chang YC, Huang SY \& Lee JJ 2012 Regulation of leptin receptor expression in human papillary thyroid cancer cells. Biomedicine \& Pharmacotherapy 66 469-473. (doi:10.1016/j.biopha. 2012.03.008)

Cheng SP, Liu CL, Hsu YC, Chang YC, Huang SY \& Lee JJ 2013 Expression and biologic significance of adiponectin receptors in papillary thyroid carcinoma. Cell Biochemistry and Biophysics 65 203-210. (doi:10.1007/ s12013-012-9419-1)

Govindan SV, Cardillo TM, Sharkey RM, Tat F, Gold DV \& Goldenberg DM 2013 Milatuzumab-SN-38 conjugates for the treatment of CD74+ cancers. Molecular Cancer Therapeutics 12 968-978. (doi:10.1158/15357163.MCT-12-1170)

Hahn-Windgassen A, Nogueira V, Chen CC, Skeen JE, Sonenberg N \& Hay N 2005 Akt activates the mammalian target of rapamycin by regulating cellular ATP level and AMPK activity. Journal of Biological Chemistry 280 32081-32089. (doi:10.1074/jbc.M502876200)

Hansen HJ, Ong GL, Diril H, Valdez A, Roche PA, Griffiths GL, Goldenberg DM \& Mattes MJ 1996 Internalization and catabolism of radiolabelled antibodies to the MHC class-II invariant chain by B-cell lymphomas. Biochemical Journal 320 293-300.

Haugen BR \& Sherman SI 2013 Evolving approaches to patients with advanced differentiated thyroid cancer. Endocrine Reviews 34 439-455. (doi:10.1210/er.2012-1038)

Hay ID, Bergstralh EJ, Goellner JR, Ebersold JR \& Grant CS 1993 Predicting outcome in papillary thyroid carcinoma: development of a reliable prognostic scoring system in a cohort of 1779 patients surgically treated at one institution during 1940 through 1989. Surgery 114 1050-1057.

He H, Jazdzewski K, Li W, Liyanarachchi S, Nagy R, Volinia S, Calin GA, Liu CG, Franssila K, Suster S et al. 2005 The role of microRNA genes in papillary thyroid carcinoma. PNAS 102 19075-19080. (doi:10.1073/ pnas.0509603102)

Hebrant A, Dom G, Dewaele M, Andry G, Tresallet C, Leteurtre E, Dumont JE \& Maenhaut C 2012 mRNA expression in papillary and anaplastic thyroid carcinoma: molecular anatomy of a killing switch. PLOS ONE 7 e37807. (doi:10.1371/journal.pone.0037807)

Henne C, Schwenk F, Koch N \& Moller P 1995 Surface expression of the invariant chain (CD74) is independent of concomitant expression of major histocompatibility complex class II antigens. Immunology $\mathbf{8 4}$ 177-182.

Huang X, Wullschleger S, Shapiro N, McGuire VA, Sakamoto K, Woods YL, McBurnie W, Fleming S \& Alessi DR 2008 Important role of the LKB1-AMPK pathway in suppressing tumorigenesis in PTEN-deficient mice. Biochemical Journal 412 211-221. (doi:10.1042/BJ20080557)

Kaufman JL, Niesvizky R, Stadtmauer EA, Chanan-Khan A, Siegel D, Horne H, Wegener WA \& Goldenberg DM 2013 Phase I, multicentre, dose-escalation trial of monotherapy with milatuzumab (humanized anti-CD74 monoclonal antibody) in relapsed or refractory multiple myeloma. British Journal of Haematology 163 478-486. (doi:10.1111/ bjh.12565)

Kim KY, Baek A, Hwang JE, Choi YA, Jeong J, Lee MS, Cho DH, Lim JS, Kim KI \& Yang Y 2009 Adiponectin-activated AMPK stimulates dephosphorylation of AKT through protein phosphatase $2 \mathrm{~A}$ activation. Cancer Research 69 4018-4026. (doi:10.1158/0008-5472.CAN-08-2641)

Kindt N, Lechien JR, Nonclercq D, Laurent G \& Saussez S 2014 Involvement of CD74 in head and neck squamous cell carcinomas. Journal of Cancer Research and Clinical Oncology 140 937-947. (doi:10.1007/s00432-0141648-9)

Klubo-Gwiezdzinska J, Costello J Jr, Patel A, Bauer A, Jensen K, Mete M, Burman KD, Wartofsky L \& Vasko V 2013 Treatment with metformin is associated with higher remission rate in diabetic patients with thyroid cancer. Journal of Clinical Endocrinology and Metabolism 98 3269-3279. (doi:10.1210/jc.2012-3799)

Lamki L, Row VV \& Volpe R 1973 Cell-mediated immunity in Graves' disease and in Hashimoto's thyroiditis as shown by the demonstration of migration inhibition factor (MIF). Journal of Clinical Endocrinology and Metabolism 36 358-364. (doi:10.1210/jcem-36-2-358)

Leng L, Metz CN, Fang Y, Xu J, Donnelly S, Baugh J, Delohery T, Chen Y, Mitchell RA \& Bucala R 2003 MIF signal transduction initiated by binding to CD74. Journal of Experimental Medicine 197 1467-1476. (doi:10.1084/jem.20030286)

Lin JD \& Chao TC 2005 Vascular endothelial growth factor in thyroid cancers. Cancer Biotherapy \& Radiopharmaceuticals 20 648-661. (doi:10.1089/cbr.2005.20.648)

Lippitz BE 2013 Cytokine patterns in patients with cancer: a systematic review. Lancet. Oncology 14 e218-e228. (doi:10.1016/S14702045(12)70582-X)

Liu CL, Cheng SP, Lin HW \& Lai YL 2014 Risk of thyroid cancer in patients with thyroiditis: a population-based cohort study. Annals of Surgical Oncology 21 843-849. (doi:10.1245/s10434-013-3363-1) 
Lue H, Thiele M, Franz J, Dahl E, Speckgens S, Leng L, Fingerle-Rowson G, Bucala R, Luscher B \& Bernhagen J 2007 Macrophage migration inhibitory factor (MIF) promotes cell survival by activation of the Akt pathway and role for CSN5/JAB1 in the control of autocrine MIF activity. Oncogene 26 5046-5059. (doi:10.1038/sj.onc.1210318)

Manning BD \& Cantley LC 2007 AKT/PKB signaling: navigating downstream. Cell 129 1261-1274. (doi:10.1016/j.cell.2007.06.009)

Martin-Ventura JL, Madrigal-Matute J, Munoz-Garcia B, Blanco-Colio LM, Van Oostrom M, Zalba G, Fortuno A, Gomez-Guerrero C, Ortega L, Ortiz A et al. 2009 Increased CD74 expression in human atherosclerotic plaques: contribution to inflammatory responses in vascular cells. Cardiovascular Research 83 586-594. (doi:10.1093/cvr/cvp141)

Meyer-Siegler KL, Iczkowski KA, Leng L, Bucala R \& Vera PL 2006 Inhibition of macrophage migration inhibitory factor or its receptor (CD74) attenuates growth and invasion of DU-145 prostate cancer cells. Journal of Immunology 177 8730-8739. (doi:10.4049/jimmunol.177.12.8730)

Miller EJ, Li J, Leng L, McDonald C, Atsumi T, Bucala R \& Young LH 2008 Macrophage migration inhibitory factor stimulates AMP-activated protein kinase in the ischaemic heart. Nature $\mathbf{4 5 1} 578-582$. (doi:10.1038/nature06504)

Nagata S, Jin YF, Yoshizato K, Tomoeda M, Song M, lizuka N, Kitamura M, Takahashi H, Eguchi H, Ohigashi H et al. 2009 CD74 is a novel prognostic factor for patients with pancreatic cancer receiving multimodal therapy. Annals of Surgical Oncology 16 2531-2538. (doi:10.1245/ s10434-009-0532-3)

Ogrinc T, Dolenc I, Ritonja A \& Turk V 1993 Purification of the complex of cathepsin L and the MHC class II-associated invariant chain fragment from human kidney. FEBS letters 336 555-559. (doi:10.1016/00145793(93)80875-U)

Phay JE \& Ringel MD 2013 Metastatic mechanisms in follicular cell-derived thyroid cancer. Endocrine-Related Cancer 20 R307-R319. (doi:10.1530/ ERC-13-0187)

Qi D, Atsina K, Qu L, Hu X, Wu X, Xu B, Piecychna M, Leng L, FingerleRowson G, Zhang J et al. 2014 The vestigial enzyme D-dopachrome tautomerase protects the heart against ischemic injury. Journal of Clinical Investigation 124 3540-3550. (doi:10.1172/JCI73061)
Ren Y, Law S, Huang X, Lee PY, Bacher M, Srivastava G \& Wong J 2005 Macrophage migration inhibitory factor stimulates angiogenic factor expression and correlates with differentiation and lymph node status in patients with esophageal squamous cell carcinoma. Annals of Surgery 242 55-63. (doi:10.1097/01.sla.0000168555.97710.bb)

Schweppe RE, Klopper JP, Korch C, Pugazhenthi U, Benezra M, Knauf JA, Fagin JA, Marlow LA, Copland JA, Smallridge RC et al. 2008 Deoxyribonucleic acid profiling analysis of 40 human thyroid cancer cell lines reveals cross-contamination resulting in cell line redundancy and misidentification. Journal of Clinical Endocrinology and Metabolism 93 4331-4341. (doi:10.1210/jc.2008-1102)

Shinohara M, Chung YJ, Saji M \& Ringel MD 2007 AKT in thyroid tumorigenesis and progression. Endocrinology 148 942-947. (doi:10.1210/en.2006-0937)

Sliwkowski MX \& Mellman I 2013 Antibody therapeutics in cancer. Science 341 1192-1198. (doi:10.1126/science.1241145)

Starlets D, Gore Y, Binsky I, Haran M, Harpaz N, Shvidel L, Becker-Herman S, Berrebi A \& Shachar I 2006 Cell-surface CD74 initiates a signaling cascade leading to cell proliferation and survival. Blood 107 4807-4816. (doi:10.1182/blood-2005-11-4334)

Verjans E, Noetzel E, Bektas N, Schutz AK, Lue H, Lennartz B, Hartmann A, Dahl E \& Bernhagen J 2009 Dual role of macrophage migration inhibitory factor (MIF) in human breast cancer. BMC Cancer 9230. (doi:10.1186/1471-2407-9-230)

Winner M, Koong AC, Rendon BE, Zundel W \& Mitchell RA 2007 Amplification of tumor hypoxic responses by macrophage migration inhibitory factor-dependent hypoxia-inducible factor stabilization. Cancer Research 67 186-193. (doi:10.1158/0008-5472.CAN-06-3292)

Xu X, Wang B, Ye C, Yao C, Lin Y, Huang X, Zhang Y \& Wang S 2008 Overexpression of macrophage migration inhibitory factor induces angiogenesis in human breast cancer. Cancer Letters 261 147-157. (doi:10.1016/j.canlet.2007.11.028)

Zheng YX, Yang M, Rong TT, Yuan XL, Ma YH, Wang ZH, Shen LS \& Cui L 2012 CD74 and macrophage migration inhibitory factor as therapeutic targets in gastric cancer. World Journal of Gastroenterology 18 2253-2261. (doi:10.3748/wjg.v18.i18.2253)

Received in final form 5 January 2015

Accepted 19 January 2015

Made available online as an Accepted Preprint

19 January 2015
(C) 2015 Society for Endocrinology Printed in Great Britain 